\title{
COGNITIVE STRATEGY IN DESIGN: THE MEASUREMENT OF ITS EFFECTS ON THE STUDENT DESIGN PRODUCT
}

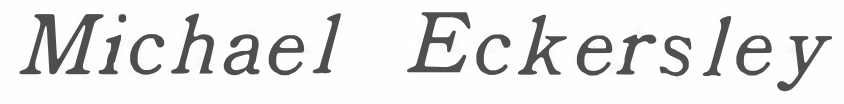

Design problem-solving is an under-studied aspect of human behavior. Since cognition is not directly observable, but rather inferred from behavior, scientific analysis of human problem solving is difficult, especially when it involves complex and ambiguous problems of design. Design problems are characteristically ill-structured problems (Reitman, 1965) whereby artefacts are constructed to attain goals (Simor, 1971). Although relatively little is known about coanitive processes in design, substantial informal knowledge has accumulated over time which is claimed to facilitate the design process (Freeman $\varepsilon$ Newell, 1971). The present study attempted to find out whether such problem solving methods as brainstorming, morphological analysis, and checklisting (as reviewed in Stein, 1974) have any effect on the quality of design problem-solving in foundation-level design students.

Since the initial work by Dow (1908), "good" design has been characterized as a sort of "visual unity" created by the successful composition of particular design elements (i.e., line, shape, value, texture, color, light) according to organizational design principles (i.e., harmony, variety, balance, movement, proportion, dominance, economy, space). Alexander (1970) defines good design as the degree to which a form fits its context, in terms of avoiding functional or aesthetic incongruities, irritants, or forces which cause "misfit" between form and context. Cross (1983) suggests that designing is a learning process wherein problems are clarified, information is sought out, and acceptable solutions are derived. Design expertise appears to develop as the novice becomes more perceptually discriminating, learns more about problem-types, problem constraints, the variety of potential solutions, and as a result, learns more about problem solving itself. The responsibility of the design educator involes transmitting design content and procedural information to students in ways which they might readily apply it to designing original and functional forms--thereby functioning as effective designers.

Simon's conception of human thinking as information processing makes readily conceivable the notion that design problems, however ambiguous, possess relative structure in terms of problem givens, problem goals, and required operations for solution. Aids to problem solving act to increase problem solving effectiveness by affecting the information processing capabilities of the problem-solver (Thomas, Lyon, \& Miller, 1977). Unfortunately, the practical effectiveness of many problem solving methods in design has not been demonstrated in controlled experiments. Only in rare instances (Thomas, Lyon, $\varepsilon$ Miller, 1977; Carroll, Thomas, $\varepsilon$ Malhotra, 1978) have basic heuristic methods been shown to aid in design problemsolving.

To summarize, the present study attempted to find out if specific 
methods of idea-generation and critical aesthetic analysis would enhance the design problem-solving behavior of foundation-level college students. Secondly, the study intended to determine whether rating scale evaluation of student designs, by a group of design professionals, would measure the relative effectiveness of student designs and the possible effects of heuristic training.

Method

\section{Subjects}

Thirty-eight freshman and sophomore students at Ball State University, Muncie, Indiana, participated in the study. The subjects were beginning foundation-level design students, registered in the Court-Design 101, TwoDimensional Design. Two intact groups comprised the sample. Experimental and control group status was determined after four weeks into the course by the toss of a coin. Although the selection of subjects was not truely random, the two groups had been blindly assigned to the experimenter from a total of over ten like design groups. Both groups met on Mondays, Wednesdays, and Fridays, in the early afternoon, for (24) 110 minute class sessions during the Winter academic quarter of 1984-1985.

\section{Procedure}

Both groups received four weeks of basic design instruction (pre-training) prior to the experiment proper. Pre-training emphasized instruction in design content information, including design elements and the principles of their organization. Emphasized also, was the student's ability to identify and effectively apply such information to the solution of basic design problems issued during the pre-training period. Upon conclusion of pre-training, both groups were issued a pre-test to measure problem solving effectiveness regarding two problem-types: a baseline problem, and a conceptual problem (see Figure 1). The conceptual problem was ambiguous and abstract, and the baseline problem was considerably more concrete and elemental. Next, a treatment of task-specific design heuristics (reformulations of brainstorming, morphogical analysis, and checklisting) was administered to the experimental group over the following seven class sessions, during which time the subjects were encouraged to use the heuristics on a series of seven practice design problems. The control group worked identical practice problems during the interim/treatment period, but did not receive the heuristic instruction. Thereafter, both groups were administered the post-test of the baseline and conceptual problems shown in Figure 1.

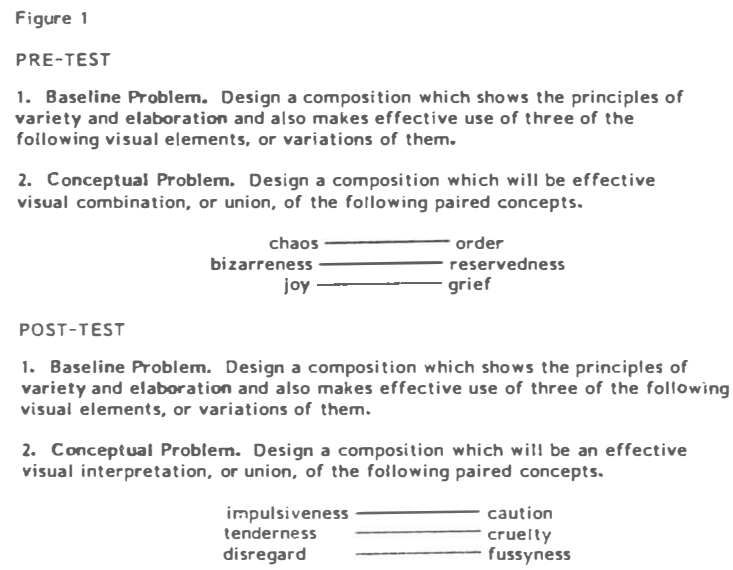




\section{Measures}

A construct of "design value" was developed for this study, based on the premises that (a) the concept of design rests on generally agreed-upon elements and principles, (b) the value of a design is pragmatically determined by a general consensus of expert agreement, (c) at least five characteristics (i.e., figural originality, conceptual originality, functionalness, aesthetic value, completeness) are essential to good design, (d) such characteristics can be operationally defined, and judgments based on such definitions can be quantified, and (e) quantified expert judgments can be averaged to validly measure the approximate "real world" value of a given design.

Student pre-test and post-test designs were evaluated by five design professionals using the Design Evaluation Rating Scale (DERS). DERS was constructed for the present study to gather and quantify expert judgments regarding particular characteristics (i.e., General Impression, Gl; Completion, CP; Figural Originality, FO; Conceptual Originality, CO; Aesthetic Value, AV; and Functionalness, FU) of figural designs. Operational definitions of each design characteristic were derived and combined with a seven-item Lickert scale, ranging from "awful" to "excellent", and ratings of each student's pretest and post-test deisgn solution were used in the data analysis. For a detailed explanation of the rating process, see Eckersley (1985).

Inter-rater reliability on the rating scale (see Table 1) shows only moderate agreement on the pre-test of the baseline problem, but high agreement for the baseline post-test, and the pre-test and post-test of the conceptual problem.

\begin{tabular}{|c|c|c|c|c|c|c|}
\hline \multirow[b]{2}{*}{ Problem } & \multicolumn{6}{|c|}{ Alpha Leval } \\
\hline & $\mathrm{GI}$ & $C P$ & Fo & co & AV & FU \\
\hline \multicolumn{7}{|l|}{ Baseline } \\
\hline Pre- & .7091 & .8409 & .7249 & .6624 & .7596 & .7606 \\
\hline Post- & 9779 & .9886 & .9884 & .9861 & .9843 & .9887 \\
\hline \multicolumn{7}{|c|}{ Conceptual } \\
\hline Pre- & 9311 & .9194 & 9419 & .9473 & .9259 & .8224 \\
\hline Post- & .9614 & .9608 & .9607 & .9354 & .9748 & .9316 \\
\hline
\end{tabular}

Note. $\mathrm{CI}=$ Ceneral Impression, $\mathrm{CP}=$ Completion

FO = Figural Originality, $\mathrm{CO}=$ Conceptual Originality,

$\mathrm{FV}=\mathrm{Figura}$
$\mathrm{AV}=$ Aesthetic Value, $\mathrm{FU}$ = Functionalness.

\section{Design}

To measure the interacting effects of period (pre-test and post-test) and group (experimental and control) in the experiment, a multivariate analysis of variance (MANOVA) technique was used. Dependent variables in the statistical analysis were: Overall Score, GI, CP, FO, CO, AV, and FU. Following the MANOVA, univariate analysis of variance (ANOVA) was utilized to measure the effects of the treatment by isolating both period and group. 
Two hypotheses were tested in the null form. Hypothesis Number One maintained that significant interaction effects would occur between period and group for the baseline problem. Hypothesis Number Two maintained that significant interaction effects would occur between period and group for the conceptual problem. Hypotheses were tested separately since the problems were determined to be sufficiently contrasting in nature.

\section{Results}

On the basis of the statistical analysis of the baseline problem (see Table 2 ), the first hypothesis was retained, suggesting a significant interaction effect between factors of period and group for each of the seven dependent variables. The between-group ANOVA for the baseline problem failed to show significant overall difference $F(10.2862)=1.41$ N.S., between the groups on the pre-test. However, it did reveal a significant overall difference $F(18.5711)-2.57, p .05$, between the groups on the post-test of the same problem. This finding suggests that whereas the groups differed significantly overall on the post-test, they were not initially different on the pre-test of the baseline problem. The within group ANOVA for the baseline problem found significant pre-test to post-test increases overall for the experimental group $F(80.5242)=11.02, p .001$, and significant performance decreases $f(38.5099)=5.27, p .01$, for the control group from pre-test to post-test on the same problem. In fact, for each dependent variable on the baseline MANOVA, the experimental group had lower pre-test scores than the control group, but had higher post-test scores than the control group. The cause(s) of this occurrence are as yet unclear. However, the motivational role of heuristic methods (and the absence of such an effect upon the control group) was a possible factor which deserves further investigation in light of this finding.

\begin{tabular}{|c|c|c|c|c|}
\hline Source & ${ }^{\text {ss }}$ Error ss & df & $\stackrel{m s}{\text { Error ms }}$ & $\mathbf{F}$ \\
\hline Overali & 30.5939 & $6 / 23$ & & $4.19 * *$ \\
\hline $\mathrm{Gl}$ & $\begin{array}{l}7.24035 \\
13.3158\end{array}$ & $1 / 28$ & $\begin{array}{c}7.24035 \\
.475561\end{array}$ & $15.22^{* * *}$ \\
\hline$C P$ & $\begin{array}{l}10.1161 \\
13.0541\end{array}$ & $1 / 28$ & $\begin{array}{c}10.1161 \\
.466219\end{array}$ & $21.70^{* * *}$ \\
\hline FO & $\begin{array}{l}8.52417 \\
10.4231\end{array}$ & $1 / 28$ & $\begin{array}{l}8.52417 \\
.372255\end{array}$ & $22.90 * 0$. \\
\hline co & $\begin{array}{l}2.58917 \\
7.96729\end{array}$ & $1 / 28$ & $\begin{array}{l}2.58917 \\
.284546\end{array}$ & $9.10 * *$ \\
\hline AV & $\begin{array}{l}9.07015 \\
11.7983\end{array}$ & $1 / 28$ & $\begin{array}{l}9.07015 \\
.421208\end{array}$ & $21.53^{* \mathrm{*} *}$ \\
\hline FU & $\begin{array}{l}7.21933 \\
11.5600\end{array}$ & $1 / 28$ & $\begin{array}{l}7.21933 \\
.421857\end{array}$ & $17.49 \%$ \\
\hline
\end{tabular}

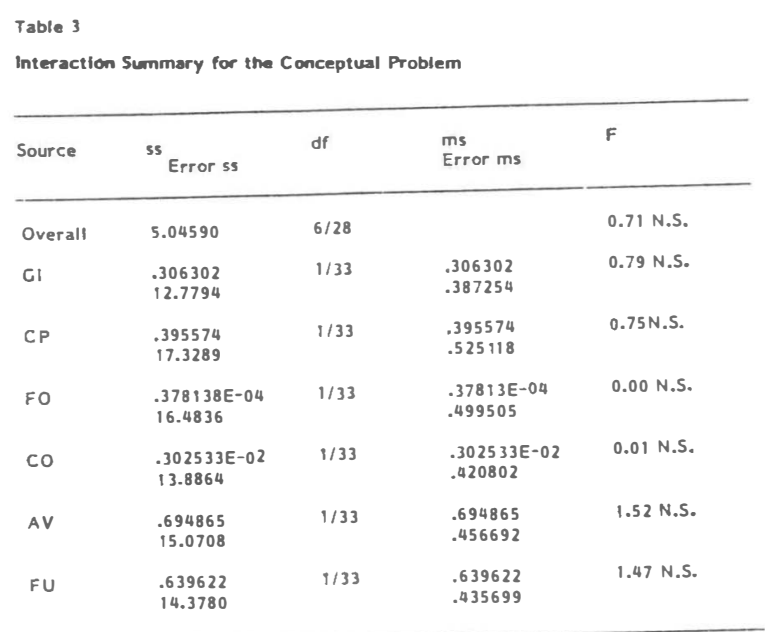

The MANOVA for the conceptual problem, on the other hand, revealed no significant interaction effect between factors of period and group for any of the seven dependent variables, thus rejecting the second hypothesis. The betweengroup ANOVA for the conceptual problem was significant pre-test to post-test increase $F(22.3542)=3.16$, $P .05$. , noted for the experimental group. However, no other within-group differences were found for any dependent variable for either the experimental group or the control group. 


\section{Discussion}

Mixed results can be reported concerning the first objective of the study, that of finding out the effects of explicit heuristic training on design problemsolving behavior in foundation-level design students. The heuristic treatment was found to be of help to students in working the more concrete baseline problem, but not helpful in working the more difficult and abstract conceptual problem. Problem structure and difficulty was a probable cause of the mixed results. Apparently the conceptual problem posed difficulties for the experimental group in applying heuristic methods, which were not posed by the baseline problem. Since the baseline problem was considerably more concrete, and provided the problem-solver with considerable figural "givens" and basic conceptual goals, the cognitive operations required to understand and apply treatment information to its solution were not beyond the capacities of the young designers. However, the conceptual problem required (a) the understanding and interpretation of highly abstract verbal concepts, (b) the development of figural equivalents to the abstract concepts, and (c) the compositional unification of figural forms according to acknowledged standards of visual design. Whether the heuristics were not appropriately matched for the conceptual problem, the problem was simply too difficult for the students, or the time limitations (approximately 100 minutes of working time per problem) contributed to the mixed results of the study, is unclear, and will have to be addressed in further experiments.

In summary, the results of the present study indicated that design problemsolving in foundation-level design students can be aided by explicit heuristic instruction, depending on (a) the relative complexity of the design problem, (b) the appropriateness of the heuristic for the problem-type, (c) the student's attitude toward, and experience with the heuristic, and (d) the amount of time for working the problem.

\section{REFERENCES}

Alexander, C. (1970). Notes on the synthesis of form. Cambridge: Harvard University Press.

Carroll, J. M., Thomas, J.C., \& Malhotra, A. (1978). Presentation and representation in design problem solving. British Journal of Psychology, 71, 143-153.

Cross, N. (1983). The relevance of cognitive syles in design education. Design Methods and Theories, 17 (1), 37-49.

Dow, A. W. (1908). The theory and practice of teaching art. New York: Teachers College, Coumbia University

Eckersley, M.E. (1985). Explicit heuristic training as a variable in design problem-solving. Dissertation Abstracts International (in press).

Freeman, P., E Jewell, A. (1971). A model for functional reasoning in design. Proceedings of Second International Joint Conference on Artificial Intelligence, (pp. 621-633) London.

Reitman, W. (1965). Cognition and thought. New York, New York: Wiley. Simon, H.A. (1971). The sciences of the artificial. Mass.: M.l.T. Press. Stein, M. (1974). Stimulating creativity. New York: Academic Press. 
Thomas, J.C., Lyon, D., \& Miller, L.A. (1977). Aids for problem solving. IBM Research Report. RC 6468. 